\title{
Characteristics of continuous venovenous hemodiafiltration in the acute treatment of inherited metabolic disorders
}

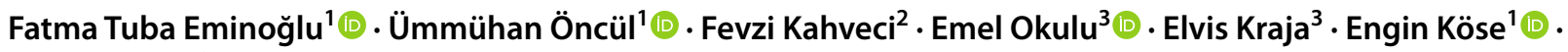 \\ Tanıl Kendirli²
}

Received: 8 July 2021 / Revised: 2 October 2021 / Accepted: 4 October 2021 / Published online: 25 October 2021

(c) The Author(s), under exclusive licence to International Pediatric Nephrology Association 2021

\begin{abstract}
Background Continuous kidney replacement therapies (CKRT) have been reported to be an effective approach to removing toxic metabolites in inborn errors of metabolism (IEM). The present study evaluates efficiency and complications of CKRT in children with IEM.

Methods Patients diagnosed with IEM who underwent CKRT in pediatric and neonatal intensive care units were analyzed. CKRT were initiated in patients with persistently high blood ammonia levels $(\geq 500 \mu \mathrm{mol} / \mathrm{L})$, blood ammonia levels $>250 \mu \mathrm{mol} / \mathrm{L}$ in the presence of moderate encephalopathy, high blood leucine levels $(\geq 1500 \mu \mathrm{mol} / \mathrm{L})$, and blood leucine levels $<1500 \mu \mathrm{mol} / \mathrm{L}$ in the presence of deteriorating neurological status or persistent metabolic acidosis.

Results Of 22 patients enrolled, nine (40.9\%) Maple syrup urine disease (MSUD), eight (36.4\%) urea cycle disorders (UCD), and five (22.7\%) organic acidemias (OA). Median age was 72.3 [9.9-1040.8] days. In total, 28 dialysis sessions were analyzed [16 (57.1\%) continuous venovenous hemodialysis, and 12 (42.9\%) continuous venovenous hemodiafiltration]. A significant decrease was noted in leucine levels (from $1608.4 \pm 885.3$ to $314.6 \pm 109.9 \mu \mathrm{mol} / \mathrm{L}$ ) of patients with MSUD, while ammonia levels were significantly decreased in patients with UCD and OA (from $1279.9 \pm 612.1$ to $85.1 \pm 21.6 \mu \mathrm{mol} / \mathrm{L}$ ). The most frequent complications of CKRT were thrombocytopenia (60.7\%), hypotension (53.6\%), and hypocalcemia (42.9\%). Median age of patients with hypotension treated with vasoactive medications was significantly lower than median age of those with normal blood pressure.
\end{abstract}

Conclusion CKRT is a reliable approach for effective and rapid removal of toxic metabolites in children with IEM, and CKRT modalities can be safely used and are well-tolerated in infants.

Keywords Ammonia $\cdot$ Leucine $\cdot$ Continuous venovenous hemodiafiltration · Inherited metabolic disorders $\cdot$ Children · Infants

\section{Introduction}

During acute metabolic crises associated with inborn errors of metabolism (IEM), toxic metabolite concentrations, such as ammonia and leucine, should be reduced as soon as possible. In hyperammonemia treatment, intravenous glucose and

Fatma Tuba Eminoğlu

tubaeminoglu@yahoo.com

1 Department of Pediatric Metabolism, Faculty of Medicine, Ankara University, Ankara, Turkey

2 Department of Pediatric Intensive Care Unit, Faculty of Medicine, Ankara University, Ankara, Turkey

3 Department of Neonatology, Faculty of Medicine, Ankara University, Ankara, Turkey lipid infusions for the support of high calorie and ammonia scavenger drugs are first-line treatments [1,2]. For hyperleucinemia, reducing leucine intake and high carbohydrate consumption are required [3], although sometimes diet and drug treatments may be insufficient, or toxic metabolite levels may increase excessively, and in such cases, extracorporeal procedures are essential to prevent neurotoxicity and death.

Continuous kidney replacement therapies (CKRT) [Continuous venovenous hemodialysis (CVVHD) and continuous venovenous hemodiafiltration (CVVHDF)] are effective in the removal of toxic metabolites in cases of acute kidney failure and acute metabolic crisis of IEM [4].

Several studies to date have been published evaluating the characteristics of CKRT in children with IEM [2, 5-8] that, overall, identify CKRT as a reliable and safe approach 
for the removal of toxic metabolites in children with IEM. Moreover, with increasing experience, the age and weight of patients who undergo CKRT gradually decreases [4], which increases such complications as vascular access problems, hypothermia, and hypotension. Identifying the possible complications and efficiency of CKRT in infants and patients with low weight has emerged as an important issue, although there is only limited information on CKRT in infants diagnosed with IEM.

This retrospective study evaluates the efficiency and complications associated with CKRT in low-weight children and infants with IEM.

\section{Methods}

\section{Patients}

All patients who underwent CKRT in the pediatric intensive care unit (PICU) and neonatal intensive care unit (NICU) between 2012 and 2020 were analyzed, and all those genetically or biochemically diagnosed with urea cycle disorders (UCD), Maple syrup urine disease (MSUD) or organic acidemias (OA) were enrolled in the study.

The toxic metabolites were determined to be ammonia for UCD- and OA-diagnosed patients and leucine for patients with MSUD. The demographic data of the patients, laboratory results and adjunctive therapies, as well as the properties of CKRT (the vascular access properties for CKRT, modality, duration of CKRT, effectiveness of treatment, changes in toxic metabolite levels during CKRT, complications associated with the procedure and the outcome) were collected for each patient retrospectively. The local ethics committee approved the study.

The calculated PRISM III (Pediatric Risk of Mortality) and PELOD-2 (Pediatric Logistic Organ Dysfunction) scores of children admitted to the PICU, and the SNAPPE (Score for Neonatal Acute Physiology with Perinatal Extension) were collected from chart reviews from the first $24 \mathrm{~h}$ of admission to the NICU [9-11].

\section{Medical therapy}

General supportive care included ventilatory and circulatory support, as well as the correction of electrolyte imbalances. To achieve an anabolic state, all patients received hypercaloric parenteral nutrition, including intravenous (iv) high dextrose-containing fluids and iv lipids of $2-3 \mathrm{~g} / \mathrm{kg} /$ day. Insulin treatment was added with a slow iv infusion (0.5-1 U/kg/hour) whenever blood glucose levels rose above $200 \mathrm{mg} / \mathrm{dL}$. All patients with hyperammonemia received nitrogen scavenger treatments as soon as possible until preparation for dialysis.

\section{Vascular access and dialysis}

During this study, our institution implemented clinical practice guidelines directing when CKRT should be used: "CKRT is initiated in patients with persistently high blood ammonia levels $(\geq 500 \mu \mathrm{mol} / \mathrm{L})$; blood ammonia levels of $>250 \mu \mathrm{mol} / \mathrm{L}$ in the presence of moderate encephalopathy; high blood leucine levels $(\geq 1500 \mu \mathrm{mol} / \mathrm{L})$; blood leucine levels of $<1500 \mu \mathrm{mol} / \mathrm{L}$ in the presence of rapidly deteriorating neurological status, moderate to severe encephalopathy and seizures, or, despite medical treatment, ongoing persistent metabolic acidosis."

A dual lumen catheter was inserted into a subclavian, internal jugular, or femoral vein using the Seldinger technique by a pediatric intensivist. The appropriate catheter size was estimated based on the patient's weight [12]. Hemodiafiltration was introduced with a Prismaflex (Baxter, USA) device, and HF20, M60, and M100 hemofilters were used (Baxter, USA). The patient's body weight was taken into account in the selection of the appropriate filter. An erythrocyte suspension, 5\% albumin, or normal saline were used to prime the extracorporeal blood circuit. Anticoagulation was achieved with unfractionated heparin or regional citrate, and the heparin dosage was adjusted according to the activated partial thromboplastin time.

During treatment, blood flow velocities were set at 4-12 $\mathrm{mL} / \mathrm{kg} / \mathrm{min}$, depending on the weight and blood pressure of the patient. Dialysate flow rates were set at 4 $\mathrm{L} / 1.73 \mathrm{~m}^{2} / \mathrm{h}$ at the outset. After blood ammonia and leucine levels were reduced to normal levels, dialysate flow rates were stepped down to $2 \mathrm{~L} / 1.73 \mathrm{~m}^{2} / \mathrm{h}$. The $100 \%$ postfilter replacement fluid rate was used to calculate the total effluent fluid rate.

The toxic metabolite reduction rate was calculated (using the formula: Initial toxic metabolite level - Posttreatment toxic metabolite level / Initial toxic metabolite level), and the percentage reduction in toxic metabolites per hour was calculated using the formula: Toxic metabolite reduction rate / Session duration [7].

\section{Statistical analysis}

Statistical analysis was conducted using IBM SPSS Statistics (Version 22.0. Armonk, NY: IBM Corp.). Categorical data were expressed as numbers and percentages (\%), while continuous data were expressed as mean \pm standard deviation (minimum-maximum) and median [25-75 percentile]. Independent and dependent parameters (before and after CKRT) categorical data were compared with a Chi-square test and a McNemar test, respectively. A Kolmogorov-Smirnov test was carried out to examine the 
normality of the numerical data. Independent continuous variables were assessed using a Mann-Whitney $U$ test. Changes in laboratory parameters after CKRT were evaluated with a Wilcoxon test. A two-tailed $p$-value of $<0.05$ was considered significant.

\section{Results}

\section{Demographic and clinic data of patients}

Of the 22 patients enrolled in the study, nine $(40.9 \%)$ were diagnosed with MSUD, eight (36.4\%) with UCD, and five (22.7\%) with OA. The median age of the patients was 72.3 [9.9-1,040.8] days, and the frequency of consanguinity was $86.4 \%$ (Table 1). The median age of UCD patients was significantly lower than that of MSUD and OA patients $(p=0.003)$ (Data not shown in table).

\section{CKRT treatment properties}

A total of 28 CKRT sessions were conducted in the PICU [11 (39.3\%)] and NICU [17 (60.7\%)], and four of the 22 patients had more than one session due to different indications for CKRT or on different hospitalization dates. The most common symptoms at admission were poor feeding/ vomiting (75\%), abnormal consciousness (75\%), and seizure (46.6\%). In none of the 28 CKRT sessions was hypotension prior to CKRT observed (Table 1).

CKRT was performed due to hyperammonemia [14 (50\%)], hyperleucinemia [14 (50\%)], abnormal consciousness [6 (21.4\%)] and metabolic acidosis [2 (7.1\%)] (Table 1). CVVHD was performed $16(57.1 \%)$ times, and patients were followed up under CVVHDF 12 (42.9\%) times. There was no significant difference between the patients with MSUD, $\mathrm{UCD}$, and OA in terms of time to start CKRT after the first manifestation of symptoms $(p=0.06)$ (Table 1$)$.

The adjunctive therapies are listed in Table 1, from which it can be seen that the most common were antibiotics $(100 \%)$, total parenteral nutrition $(100 \%)$, vasoactive medications (53.6\%), and intravenous bicarbonate treatment $(42.9 \%)$. It was observed that all vasoactive medications were initiated during CKRT.

For the administration of ventilator support, noninvasive ventilation (NIV) and mechanical invasive ventilation (MIV) were performed on six (21.4\%) and 18 (64.3\%) patients, respectively, and two (7.1\%) patients were followed up under extracorporeal membrane oxygenation (ECMO).

The mean mortality scores (PRISM III, PELOD-2, SNAPPE) before CKRT are presented in Table 1. There were no significant differences between the MSUD-, UCD- and OA-diagnosed patients in terms of PRISM III, PELOD-2 and SNAPPE scores $(p=0.245, p=0.175$, and $p=0.530$, respectively) (Table 1).

Anticoagulation was initiated with heparin (78.6\%) and citrate $(21.4 \%)$ for all sessions. Red blood cell transfusions were performed in 20 (71.4\%) CKRT sessions, and platelet transfusions were given in 10 (35.7\%) CKRT sessions (Table 2). The most commonly used vascular access was the internal jugular vein $(75 \%)$, and the most frequently used catheter size was $7.0 \mathrm{Fr}$ (64.3\%) (Table 2).

\section{Laboratory parameters}

A significant decrease was detected in the leucine levels of patients with MSUD following CKRT, and a significant reduction in ammonia levels was observed in patients with UCD and OA following CKRT (Table 3). The changes in serum leucine and ammonia levels during CKRT are presented in Fig. 1. In the MSUD patients, the mean leucine reduction rate and the mean leucine reduction rate per hour were determined as $74.2 \pm 14.3 \%(45.4-88.9)$ and $2.8 \pm 1.7 \%$ (1.0-6.3), respectively. The mean ammonia reduction rate was calculated as $91.2 \pm 6.3 \%$ (79.5-97.1), and the mean ammonia reduction rate per hour was $4.7 \pm 1.7 \%$ (2.6-7.7).

An evaluation of other laboratory parameters revealed a statistically significant decrease in platelet count, blood urea nitrogen (BUN), creatinine, potassium, and phosphorus levels following dialysis treatment (Table 3 ).

With CKRT, the mean value of the platelet count in a blood test decreased from $270.7 \pm 167.8 \times 10^{9} / \mathrm{L}$ to $106.9 \pm 79.5 \times 10^{9} / \mathrm{L}(p<0.0001)$ after CKRT, while the mean BUN level decreased from $7.8 \pm 5.8$ to $4.0 \pm 3.3 \mathrm{mg} /$ $\mathrm{dL}(p=0.004)$. The mean serum potassium level decreased from $3.9 \pm 1.0$ to $3.4 \pm 0.7 \mathrm{mmol} / \mathrm{L}(p=0.015)$ and the mean serum phosphorus level decreased from $4.6 \pm 1.5$ to $3.2 \pm 2.0 \mathrm{mg} / \mathrm{dL}(p=0.009)$ after CKRT (Table 3$)$. There were no significant differences in the laboratory parameters associated with the CVVHD and CVVDHF modes (data not shown in table).

\section{CKRT complications}

The most frequent complications of CKRT were thrombocytopenia (60.7\%), hypotension (53.6\%), and hypocalcemia (42.9\%) (Table 4).

A comparison of demographic and clinical findings of CVVHDF and CVVHD is presented in Table 5. The median age was significantly lower in the patients under CVVHDF (10.5 [3.3-121] days) than under CVVHD (1027 [49.3-1592.3] days). While the diagnosis of seven (58.3\%) patients treated with CVVHDF was UCD, 11 (68.8\%) of the CVVHD treatments were performed on MSUD patients $(p=0.0028)$. There was no significant difference in the PRISM III, PELOD-2, and SNAPPE 
Table 1 Demographic and clinical characteristics of patients undergoing CKRT

\begin{tabular}{|c|c|c|c|c|}
\hline Number of patients & $\operatorname{MSUD}(n=9)$ & $\mathrm{UCD}(n=8)$ & $\mathrm{OA}(n=5)$ & Total $(N=22)$ \\
\hline Number of dialysis, $n$ & 14 & 9 & 5 & 28 \\
\hline \multicolumn{5}{|l|}{ Baseline characteristics } \\
\hline Gender (male), $n(\%)$ & $5(55.6)$ & $5(62.5)$ & $2(40)$ & $12(54.5)$ \\
\hline $\begin{array}{l}\text { Age at dialysis (days), } \\
\text { median [25th-75th percentile] }\end{array}$ & $593[34-1290.7]]$ & $4[3-29]$ & $1020[482-4035]$ & $72.3[9.9-1040.8]$ \\
\hline Consanguinity, $n(\%)$ & $9(100)$ & $5(62.5)$ & $5(100)$ & $19(86.4)$ \\
\hline Weight at dialysis $(\mathrm{kg})$, mean $\pm \mathrm{SD}(\min -\max )$ & $9.1 \pm 6.3(2.5-19.5)$ & $3.8 \pm 1.1(3-6.5)$ & $14 \pm 8.9(3.7-27)$ & $8.3 \pm 6.7(2.5-27)$ \\
\hline PICU/NICU, $n(\%)$ & $11(78.6) / 3(21.4)$ & $2(22.2) / 7(77.8)$ & $4(80) / 1(20)$ & $17(60.7) / 11(39.3)$ \\
\hline \multicolumn{5}{|c|}{ Initial mortality score, median $\left[25^{\text {th }}\right.$ percentile $-75^{\text {th }}$ percentile $]$} \\
\hline PRISM III $(n=17)$ & $12[9-19]$ & $21[13-29]$ & $15.5[14.3-25.8]$ & $13[8-15.5]$ \\
\hline PELOD-2 $(n=17)$ & $9[7-12]$ & $12[11-21]$ & $11.5[4-19.8]$ & $10[0-20.5]$ \\
\hline $\operatorname{SNAPPE}(n=11)$ & $31[21-35]$ & $31[24-38]$ & $32[30-35]$ & $31[24-35]$ \\
\hline \multicolumn{5}{|l|}{ Symptoms and findings on admission, $\mathrm{n}(\%)$} \\
\hline Poor feeding/vomiting & $12(85.7)$ & $4(44.4)$ & $5(100)$ & $21(75.0)$ \\
\hline Abnormal consciousness & $10(71.4)$ & $7(77.8)$ & $4(80)$ & $21(75.0)$ \\
\hline Seizures & $9(64.3)$ & $4(44.4)$ & $0(0)$ & $13(46.4)$ \\
\hline Metabolic acidosis & $4(28.6)$ & $4(44.4)$ & $4(80)$ & $12(42.9)$ \\
\hline Sepsis & $5(35.7)$ & $2(22.2)$ & $4(80)$ & $11(39.3)$ \\
\hline Circulatory disorder & $2(14.3)$ & $7(77.8)$ & $1(20)$ & $10(35.7)$ \\
\hline Respiratory failure & $2(14.3)$ & $6(66.7)$ & $2(40)$ & $10(35.7)$ \\
\hline Hypotension prior to CKRT & $0(0.0)$ & $0(0.0)$ & $0(0.0)$ & $0(0.0)$ \\
\hline \multicolumn{5}{|l|}{ CKRT indications, $n(\%)$} \\
\hline Hyperleucinemia & $14(100)$ & $0(0)$ & $0(0)$ & $14(50.0)$ \\
\hline Hyperammonemia & $0(0)$ & $9(100)$ & $5(100)$ & $14(50.0)$ \\
\hline Abnormal consciousness & $4(28.6)$ & $0(0)$ & $2(40)$ & $6(21.4)$ \\
\hline Metabolic acidosis & $0(0)$ & $0(0)$ & $2(40)$ & $2(7.1)$ \\
\hline \multicolumn{5}{|l|}{ Mode of CKRT, $n(\%)$} \\
\hline CVVHD & 11 (78.6) & $2(22.2)$ & $3(60.0)$ & $16(57.1)$ \\
\hline CVVHDF & $3(21.4)$ & $7(77.8)$ & $2(40.0)$ & $12(42.9)$ \\
\hline $\begin{array}{l}\text { Time to start CKRT after the first symptom (h), } \\
\text { mean } \pm \text { SD (min-max) }\end{array}$ & $119.4 \pm 195.8(6.0-108.0)$ & $33.1 \pm 30.7(8-108)$ & $106.0 \pm 57.3(50.0-168.0)$ & $89.3 \pm 144.3(6-720)$ \\
\hline \multicolumn{5}{|l|}{ Adjunctive therapies, $n(\%)$} \\
\hline Antibiotherapy & $14(100)$ & $9(100)$ & $5(100)$ & $28(100)$ \\
\hline Total parenteral nutrition & $14(100)$ & $9(100)$ & $5(100)$ & $28(100)$ \\
\hline Inotropes & $4(28.6)$ & $7(77.8)$ & $4(80)$ & $15(53.6)$ \\
\hline Bicarbonate (iv) & $4(28.6)$ & $3(33.3)$ & $5(100)$ & $12(42.9)$ \\
\hline Sodium phenylacetate + sodium benzoate (iv) & $0(0)$ & $8(88.9)$ & $1(20)$ & $9(32.1)$ \\
\hline L-carnitine & $0(0)$ & $2(22.2)$ & $5(100)$ & $7(25.0)$ \\
\hline Carglumic Acid & $0(0)$ & $5(55.6)$ & $3(60)$ & $8(28.6)$ \\
\hline Arginine & $0(0)$ & $7(77.8)$ & $0(0)$ & $7(25.0)$ \\
\hline Sodium phenylbutyrate (po) & $0(0)$ & $1(11.1)$ & $1(20)$ & $2(7.1)$ \\
\hline Hydroxocobalamin & $0(0)$ & $0(0)$ & $2(40)$ & $2(7.1)$ \\
\hline Citrulline & $0(0)$ & $1(11.1)$ & $0(0)$ & $1(3.6)$ \\
\hline \multicolumn{5}{|l|}{ Ventilatory Support* } \\
\hline NIV, n (\%) & $4(28.6)$ & $2(22.2)$ & $0(0)$ & $6(21.4)$ \\
\hline MIV, n (\%) & $5(35.7)$ & $9(100)$ & $4(80)$ & $18(64.3)$ \\
\hline $\operatorname{MIV}($ day $)$, mean \pm SD $(\min -\max )$ & $12.2 \pm 19.5(2-47)$ & $6.63 \pm 5(2-17)$ & $12 \pm 15.3(4-35)$ & $9.53 \pm 12.6(2-47)$ \\
\hline ECMO n $(\%)$ & $1(7.1)$ & $0(0)$ & $1(20)$ & $2(7.1)$ \\
\hline
\end{tabular}

$C V V H D$ continuous venovenous hemodialysis, $C V V H D F$ continuous venovenous hemodiafiltration, $C K R T$ continuous kidney replacement therapy, ECMO extracorporeal membrane oxygenation, $i v$ intravenous, max maximum, min minimum, MIV mechanical invasive ventilation, $M S U D$ maple syrup urine disease, $N I C U$ neonatal intensive care unit, $N I V$ non-invasive ventilation, $O A$ organic acidemia, $P E L O D-2$ pediatric logistic organ dysfunction, PICU pediatric intensive care unit, PRISM III pediatric risk of mortality, po per oral, SD standard deviation, SNAPPE score for neonatal acute physiology with perinatal extension, UCD urea cycle disorder, *:Ventilatory support during ICU stay 
Table 2 Preparation features and settings of CKRT

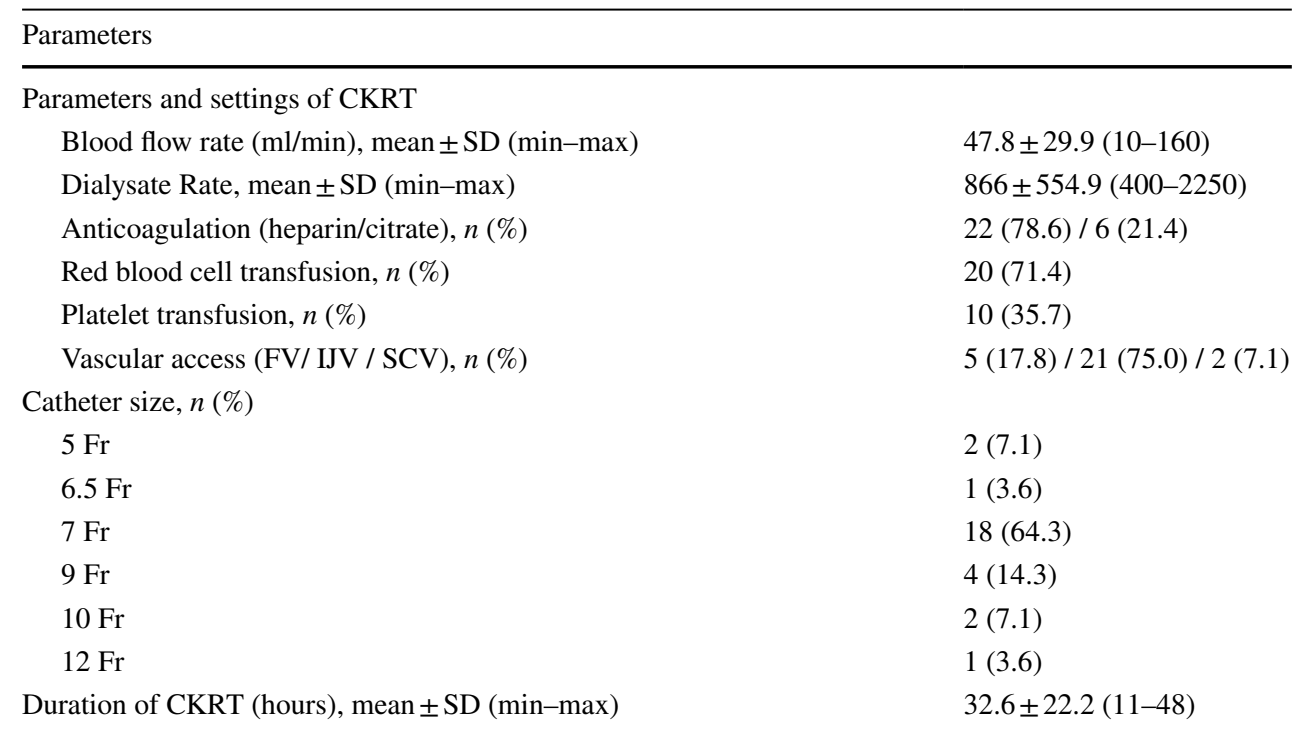

$C K R T$ continuous kidney replacement therapy, $\max$ maximum, $\min$ minimum, $F V$ femoral vein, $I J V$ internal jugular vein, $S C V$ superior vena cava, $S D$ standard deviation

Table 3 Laboratory parameters before and after CKRT

\begin{tabular}{|c|c|c|c|}
\hline Parameters & Before CKRT & After CKRT & $p$ \\
\hline Leucine $(\mu \mathrm{mol} / \mathrm{L}), \operatorname{mean} \pm \mathrm{SD}(\min -\max )$ & $1608.4 \pm 885.3(733-3330)$ & $314.6 \pm 109.9(139-580)$ & $<0.0001 *$ \\
\hline Plasma ammonia $(\mu \mathrm{mol} / \mathrm{L})$, mean $\pm \mathrm{SD}(\min -\max )$ & $1279.9 \pm 612.1(451-2626)$ & $85.1 \pm 21.6(56-140)$ & $<0.0001 *$ \\
\hline $\mathrm{LDH}(\mathrm{U} / \mathrm{L})$, mean $\pm \mathrm{SD}(\min -\max )$ & $600.9 \pm 370.5(178-1551)$ & $806.6 \pm 948.4(250-5271)$ & 0.424 \\
\hline LDH level in normal range, $n(\%)$ & $15(53.6)$ & $15(53.6)$ & 1.000 \\
\hline $\mathrm{Hb}(\mathrm{g} / \mathrm{dL})$, mean $\pm \mathrm{SD}(\min -\max )$ & $10.45 \pm 2.5(6.9-16.8)$ & $10.6 \pm 2.0(6.6-15.6)$ & 0.466 \\
\hline Hb level in normal range, $n(\%)$ & $16(57.1)$ & $15(53.6)$ & 1.000 \\
\hline $\mathrm{WBC}\left(10^{9} / \mathrm{L}\right)$, mean $\pm \mathrm{SD}(\min -\max )$ & $12.5 \pm 7.9(3.3-35.5)$ & $9.9 \pm 5.7(3.2-21.4)$ & 0.068 \\
\hline WBC level in normal range, $n(\%)$ & $19(67.9)$ & $21(75.0)$ & 0.727 \\
\hline Neutrophils $\left(10^{9} / \mathrm{L}\right)$, mean $\pm \mathrm{SD}(\min -\max )$ & $7.0 \pm 4.9(1.1-18.2)$ & $5.7 \pm 4.4(1.0-16.3)$ & 0.203 \\
\hline Neutrophils level in normal range, $n(\%)$ & $25(89.3)$ & $22(78.6)$ & 0.375 \\
\hline Platelets $\left(10^{9} / \mathrm{L}\right)$, mean $\pm \mathrm{SD}(\min -\max )$ & $270.7 \pm 167.8(69.0-678.0)$ & $106.9 \pm 79.5(10.0-327.7)$ & $<0.0001^{*}$ \\
\hline Platelet count in normal range, $n(\%)$ & $18(64.3)$ & $6(21.4)$ & $0.004 *$ \\
\hline $\mathrm{BUN}(\mathrm{mg} / \mathrm{dL})$ mean $\pm \mathrm{SD}(\min -\max )$ & $7.8 \pm 5.8(1-27)$ & $4.0 \pm 3.3(1-14)$ & $0.004^{*}$ \\
\hline BUN level in normal range, $n(\%)$ & $16(57.1)$ & $6(21.4)$ & $0.021^{*}$ \\
\hline Creatine $(\mathrm{mg} / \mathrm{dL})$, mean $\pm \mathrm{SD}(\min -\max )$ & $0.58 \pm 0.57(0.11-2.45)$ & $0.33 \pm 0.32(0.1-1.6)$ & $0.003^{*}$ \\
\hline Creatine level in normal range, $n(\%)$ & $21(75.0)$ & $27(96.4)$ & 0.07 \\
\hline Sodium $(\mathrm{mmol} / \mathrm{L})$, mean $\pm \mathrm{SD}(\min -\max )$ & $139.7 \pm 8.5(127-157)$ & $139.0 \pm 3.7(133-147)$ & 0.647 \\
\hline Sodium level in normal range, $n(\%)$ & $12(42.9)$ & $24(85.7)$ & $0.004 *$ \\
\hline Potassium $(\mathrm{mmol} / \mathrm{L})$, mean $\pm \mathrm{SD}(\min -\max )$ & $3.9 \pm 1.0(2-6.5)$ & $3.4 \pm 0.7(2.4-5.3)$ & 0.015 \\
\hline Potassium level in normal range, $n(\%)$ & $19(67.9)$ & $9(32.1)$ & $0.006^{*}$ \\
\hline Calcium $(\mathrm{mg} / \mathrm{dL})$ mean $\pm \mathrm{SD}(\min -\max )$ & $8.4 \pm 2.1(5.3-15.3)$ & $9.0 \pm 1.2(7.1-13.1)$ & 0.086 \\
\hline Calcium level in normal range, $n(\%)$ & $17(60.7)$ & $17(60.7)$ & 1.000 \\
\hline Phosphorus $(\mathrm{mg} / \mathrm{dL})$, mean $\pm \mathrm{SD}(\min -\max )$ & $4.6 \pm 1.5(1.9-9.3)$ & $3.2 \pm 2.0(1.2-10.9)$ & $0.009 *$ \\
\hline Phosphorus level in normal range, $n(\%)$ & $21(75.0)$ & $8(28.6)$ & $0.007^{*}$ \\
\hline Albumin $(\mathrm{g} / \mathrm{dL})$, mean $\pm \mathrm{SD}(\min -\max )$ & $2.9 \pm 0.7(2.1-4.9)$ & $2.8 \pm 0.5(1.8-4.2)$ & 0.173 \\
\hline Albumin level in normal range, $n(\%)$ & $11(39.3)$ & $9(32.1)$ & 0.727 \\
\hline
\end{tabular}

$C K R T$ continuous kidney replacement therapy, $L D H$ lactate dehydrogenase, max maximum, min minimum, $H b$ hemoglobin, $W B C$ white blood cell, $B U N$ blood urea nitrogen, $*=p<0.05$ 

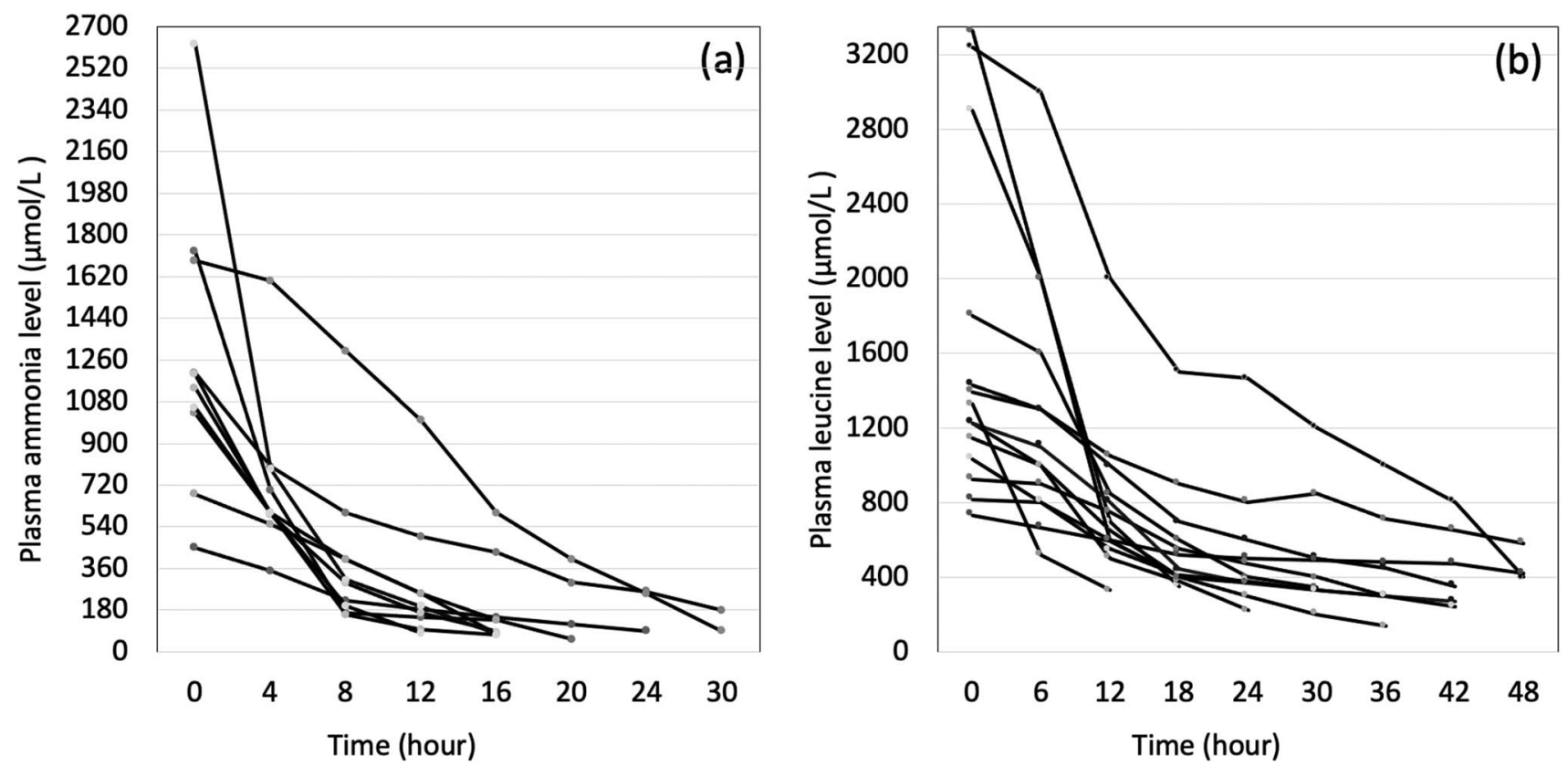

Fig. 1 (a) Changes in serum ammonia levels during CKRT in patients with hyperammonemia. (b) Changes in serum leucine levels during CKRT in patients with MSUD

Table 4 The complications and outcomes of CKRT

\begin{tabular}{ll}
\hline CKRT complications & $\begin{array}{l}\text { Total }(N=28) \\
n(\%)\end{array}$ \\
\hline Thrombocytopenia & $17(60.7)$ \\
Hypotension & $15(53.6)$ \\
Hypocalcemia & $12(42.9)$ \\
Hypokalemia & $12(42.9)$ \\
Hypophosphatemia & $10(35.7)$ \\
Bleeding & $8(28.6)$ \\
Hypothermia & $7(25.0)$ \\
Hypomagnesemia & $5(17.9)$ \\
Hyponatremia & $3(10.7)$ \\
Hypoalbuminemia & $2(7.1)$ \\
Pneumothorax & $1(3.7)$ \\
Thrombosis & $1(3.7)$ \\
Cardiac arrest & $1(3.6)$ \\
Outcome & $8(28.6)$ \\
Death, $n(\%)$ &
\end{tabular}

CKRT continuous kidney replacement therapy

scores of the CVVHDF and CVVHD groups. Hypotension was statistically more frequently observed in CVVHDF (75.0\%) than CVVHD (37.5\%) $(p=0.049)$ (Table 5).

In total, eight (28.6\%) patients died, with a higher mortality rate detected in CVVHDF (50.0\%) than CVVHD $(12.5 \%)(p=0.044)$ in a comparison of CKRT modalities (Table 5).
An analysis of the demographic and clinical findings and the clinical outcomes of CKRT are presented in Table 6. There were no significant differences in the age and diagnosis of the patients who survived and those who died. While no relationship was detected between mortality and PRISM III $(p=0.060)$, PELOD-2 scores were higher in the patients who died (22 [2-32]) than in those who survived (10 [0-16.5]) $(p=0.023)$. No relationship between SNAPPE and mortality was identified in newborn patients $(p=0.610)$, and the complications associated with CKRT were not different between the two groups (Table 6).

\section{Evaluation of the relationship between the properties and complications of CKRT and patient age}

The patients treated with vasoactive medications and administered MIV were younger than the others $(p=0.019$ and $p<0.0001)$. The median age of the patients with hypotension (15 [4-180] days) was significantly lower than the median age of those with normal blood pressure (1042 [60-1745.5] days) (Table 7). While no significant difference was recorded in the age of platelet-transfused patients and those who were not transfused (Table 7), the requirement for platelet transfusion was higher in patients under the age of 3 months (57.1\%) than in patients older than 3 months $(15.4 \%)(p=0.031)$ (data not shown in table). 
Table 5 Comparison of demographic and clinical findings of CVVHDF and CVVHD

\begin{tabular}{|c|c|c|c|}
\hline Parameters & CVVHDF $(n=12)$ & CVVHD $(n=16)$ & $p$ \\
\hline Gender (male), $n(\%)$ & $6(50.0)$ & $6(37.5)$ & 0.508 \\
\hline Age at dialysis (days), median [25th-75th percentile] & $10.5[3.3-121]$ & $1027[49.3-1592.3]$ & $0.001 *$ \\
\hline Diagnosis (UCD/MSUD/OA), $n(\%)$ & $7(58.3) / 3(25.0) / 2(16.7)$ & $2(12.5) / 11(68.8) / 3(10.7)$ & $0.028 *$ \\
\hline PICU/NICU, $n(\%)$ & $9(75.0) / 3(25.0)$ & $2(12.5) / 14(87.5)$ & $0.001 *$ \\
\hline Consanguinity, $n(\%)$ & $10(83.3)$ & $15(93.8)$ & 0.560 \\
\hline PRISM III, median [25th-75th percentile] & $14.0[13.0-14.0]$ & $11.0[7.8-15.3]$ & 0.300 \\
\hline PELOD-2, median [25th-75th percentile] & $20.0[0.0-20.0]$ & $6[0-15.0]$ & 0.676 \\
\hline SNAPPE, median [25th-75th percentile] & $31.0[22.5-35.0]$ & $34.5[31.0-34.5]$ & 0.436 \\
\hline $\begin{array}{l}\text { Time to start CKRT after the first symptom (h), median } \\
\text { [25th-75th percentile] }\end{array}$ & 60 [24.0-105.0] & $31.5[15-90]$ & 0.537 \\
\hline \multicolumn{4}{|l|}{ CKRT complications } \\
\hline Thrombocytopenia & $8(66.7)$ & $9(56.3)$ & 0.576 \\
\hline Hypotension & $9(75.0)$ & $6(37.5)$ & $0.049 *$ \\
\hline Hypocalcemia & $7(58.3)$ & $5(31.3)$ & 0.152 \\
\hline Hypokalemia & $6(50.0)$ & $6(37.5)$ & 0.508 \\
\hline Hypophosphatemia & $6(50.0)$ & $4(25.0)$ & 0.172 \\
\hline Bleeding & $4(33.3)$ & $4(25.0)$ & 0.691 \\
\hline Hypothermia & $3(25.0)$ & $4(25.0)$ & 1.000 \\
\hline Hypomagnesemia & $2(16.7)$ & $3(18.8)$ & 1.000 \\
\hline Hyponatremia & $1(8.3)$ & $2(12.5)$ & 1.000 \\
\hline Hypoalbuminemia & $1(8.3)$ & $1(3.6)$ & 1.000 \\
\hline Pneumothorax & $1(8.3)$ & $0(0)$ & NA \\
\hline Thrombosis & $1(8.3)$ & $0(0)$ & NA \\
\hline Cardiac arrest & $0(0)$ & $1(3.6)$ & NA \\
\hline \multicolumn{4}{|l|}{ Outcome } \\
\hline Death, n (\%) & $6(50.0)$ & $2(12.5)$ & $0.044 *$ \\
\hline
\end{tabular}

$C V V H D$ continuous venovenous hemodialysis, $C V V H D F$ continuous venovenous hemodiafiltration, $C K R T$ continuous kidney replacement therapy, $M S U D$ maple syrup urine disease, NICU neonatal intensive care unit, $O A$ organic acidemia, $P E L O D-2$ pediatric logistic organ dysfunction, $P I C U$ pediatric intensive care unit, PRISM III pediatric risk of mortality, SNAPPE score for neonatal acute physiology with perinatal extension, $U C D$ urea cycle disorder. ${ }^{*}=p<0.05$

\section{Discussion}

High toxic metabolite levels in the neonatal and early childhood periods, especially hyperammonemia and hyperleucinemia, can lead to cerebral edema, irreversible central nervous system damage, and even death in patients with UCD, OA, and MSUD. Accordingly, the elimination of toxic metabolites to avoid neurological complications should be considered a medical emergency. CKRT is an effective treatment for acute crises in some IEM [13, 14]. In the present study, CKRT was shown to quickly reduce toxic metabolites (ammonia, leucine) in patients diagnosed with IEM.

In recent decades, CKRT has emerged as an essential approach to treating acute metabolic crises in children [15], and experience in the use of CKRT in infants weighing $10 \mathrm{~kg}$ or less has improved [16]. There have, however, been only a limited number of studies evaluating CKRT in patients diagnosed with IEM to date $[6-8,15]$. The primary strength of the present study is its status as the study with the most extensive CKRT series (28 sessions) in patients diagnosed with IEM to date, and the fact that more than half of the patients (15 patients 53.6\%) were under the age of 3 months. This report describes the significant contribution of CVVHD/CVVHDF to the treatment of acute metabolic crises not only in children but also in infants under the age of 3 months.

While there is no current recommended level for starting extracorporeal detoxification for the management of hyperleucinemia, it is known that CKRT may be required if leucine levels exceed $1500 \mu \mathrm{mol} / \mathrm{L}$ [17]. Aygun et al. reported an initial mean leucine level in patients with MSUD of $1777 \pm 831.6 \mu \mathrm{mol} / \mathrm{L}$ [6], while another study reported an initial leucine level of $1648 \pm 623.8 \mu \mathrm{mol} / \mathrm{L}$ [7]. In the present study, the mean initial plasma leucine level value was $1608 \pm 885.3 \mu \mathrm{mol} / \mathrm{L}$, and the initial plasma leucine levels of nine patients were $<1500 \mu \mathrm{mol} / \mathrm{L}$. In these sessions, CKRT was started due to the patients' rapidly deteriorating neurological status, moderate to severe encephalopathy, and 
Table 6 The analysis of demographic and clinical findings on the clinical outcome of CKRT

\begin{tabular}{|c|c|c|c|}
\hline Parameters & Survived $(n=20)$ & Death $(n=8)$ & $p$ \\
\hline Gender (male), $n(\%)$ & $10(50)$ & $2(25)$ & 0.401 \\
\hline Age at dialysis (days), median [25th-75th percentile] & $124[14.8-124]$ & $46[4-758]$ & 0.281 \\
\hline Diagnosis (UCD/MSUD/OA), $n(\%)$ & $6(30) / 12(60) / 2(10)$ & $3(37.5) / 2(25) / 3(37.5)$ & 0.262 \\
\hline Consanguinity, $n(\%)$ & $18(96)$ & $7(87.5)$ & 1.000 \\
\hline PICU/NICU, $n(\%)$ & $13(65) / 7(35)$ & $4(50) / 4(50)$ & 0.671 \\
\hline \multicolumn{4}{|l|}{ Scores, median [25th-75th percentile] } \\
\hline PRISM III & $9[7.5-14.5]$ & $15[14-24.8]$ & 0.060 \\
\hline PELOD-2 & $10[0-16.5]$ & $22[2-32]$ & $0.023 *$ \\
\hline SNAPPE & $31[24-38]$ & $33[23.5-35]$ & 0.610 \\
\hline $\begin{array}{l}\text { Time to start CKRT after the first symptom (h), median [25th- } \\
\text { 75th percentile] }\end{array}$ & $31[12-90]$ & $72[30-105]$ & 0.218 \\
\hline \multicolumn{4}{|l|}{ CKRT complications } \\
\hline Thrombocytopenia & $13(65.0)$ & $4(50.0)$ & 0.671 \\
\hline Hypotension & $10(50.0)$ & $5(62.5)$ & 0.686 \\
\hline Hypocalcemia & $8(40.0)$ & $4(50.0)$ & 0.691 \\
\hline Hypokalemia & $10(50.0)$ & $2(25.0)$ & 0.401 \\
\hline Hypophosphatemia & $6(30.0)$ & $4(50.0)$ & 0.578 \\
\hline Bleeding & $6(30.0)$ & $2(25.0)$ & 0.791 \\
\hline Hypothermia & $6(30.0)$ & $1(12.5)$ & 0.334 \\
\hline Hypomagnesemia & $4(20.0)$ & $1(12.5)$ & 1.000 \\
\hline Hyponatremia & $1(5.0)$ & $2(25.0)$ & 0.188 \\
\hline Hypoalbuminemia & $0(0)$ & $2(25.0)$ & NA \\
\hline Pneumothorax & $0(0)$ & $1(12.5)$ & NA \\
\hline Thrombosis & $1(5.0)$ & $0(0)$ & NA \\
\hline Cardiac arrest & $1(5.0)$ & $0(0)$ & NA \\
\hline
\end{tabular}

$C K R T$ continuous kidney replacement therapy, MSUD maple syrup urine disease, NICU neonatal intensive care unit, $O A$ organic acidemia, $P E L O D-2$ pediatric logistic organ dysfunction, PICU pediatric intensive care unit, PRISM III pediatric risk of mortality, PICU pediatric intensive care unit, SNAPPE score for neonatal acute physiology with perinatal extension, $U C D$ urea cycle disorder, $*=p<0.05$

Table 7 Evaluation of the relationship between properties, and the complications of CKRT and age of patients

\begin{tabular}{lccc}
\hline Parameters & \multicolumn{2}{c}{ Age at dialysis (days), median [25th-75th percentile] } & \multirow{2}{*}{$p$} \\
\cline { 2 - 3 } & Yes & No \\
\hline Adjunctive Therapies & & & \\
$\quad$ Inotropes & $28[4-180]$ & $1037[30-1745.5]$ & $0.019^{*}$ \\
NIV & $28[10.5-72.5]$ & $570[12.3-1282.5]$ & 0.232 \\
MIV & $16[4-159]$ & $1039.5[739.3-1744.3]$ & $<0.0001^{*}$ \\
Red blood cell transfusion & $52[4.8-1040.8]$ & $166[21.3-1562.3]$ & 0.601 \\
Platelet transfusion & $32[6.3-297.8]$ & $607[11.5-1718.3]$ & 0.133 \\
CKRT complications & & & \\
Thrombocytopenia & $43[5.5-1027]$ & $152[28-1743]$ & 0.191 \\
Hypotension & $15[4-180]$ & $1042[60-1745.5]$ & $0.003 *$ \\
Hypocalcemia & $35.5[8.8-1036.5]$ & $114.5[7.3-1114.3]$ & 0.537 \\
Hypokalemia & $48[4-820.5]$ & $518.5[14.3-1115.5]$ & 0.423 \\
Hypophosphatemia & $83.5[4-1719.5]$ & $72.5[163-1034.8]$ & 0.869 \\
Bleeding & $1035.5[18.3-1543]$ & $55.5[4-1005]$ & 0.237 \\
Hypothermia & $28[4-1034]$ & $152[14.5-1091]$ & 0.348 \\
Hypomagnesemia & $1042[16-1729]$ & $68[7-1034]$ & 0.380 \\
\hline
\end{tabular}

$C K R T$ continuous kidney replacement therapy, MIV mechanical invasive ventilation, NIV non-invasive ventilation, *: $p<0.05$ 
seizures. We believe that with increased experience, CKRT will be more frequently performed in cases with leucine levels below $1500 \mu \mathrm{mol} / \mathrm{L}$ in MUSD-diagnosed patients with abnormal consciousness, as observed in the present study.

An approach involving the cessation of protein consumption and a higher calorie intake was applied to all patients. According to the most recent guidelines related to the management of hyperammonemia in pediatric patients, CKRT should be initiated in patients with persistently high blood ammonia levels $(\geq 500 \mu \mathrm{mol} / \mathrm{L})$ or blood ammonia levels of $>250 \mu \mathrm{mol} / \mathrm{L}$ in the presence of moderate encephalopathy [4]. Consistently, the mean value of the initial plasma ammonia levels was $1279.9 \pm 612.1 \mu \mathrm{mol} / \mathrm{L}$ and the minimum value of the plasma ammonia level was $451 \mu \mathrm{mol} / \mathrm{L}$. The observed treatment modalities were consistent with those recommended in published guidelines [1, 18].

Continuous kidney replacement therapy has led to improvements in the outcomes of dialysis complications and is superior to intermittent hemodialysis in maintaining hemodynamic stability and preventing a re-increase of toxic metabolites [4]. Multiple CKRT techniques have been developed, all of which are safe and efficacious, and among which, CVVHD enables a higher toxic metabolite clearance rate than continuous venovenous hemofiltration $(\mathrm{CVVH})$ for the management of hyperammonemia and hyperleucinemia $[4,19,20]$. In the present study, the CVVHD (57.1\%) and CVVHDF (42.9\%) modalities were analyzed, and the CVVHD modality was found to be used in most MSUD dialysis sessions (78.6\%), as the rapid removal of leucine is not as important as ammonia removal. On the other hand, the CVVHDF mode was frequently preferred in the patients' hyperammonemia sessions (64.3\%), although the authors identified no significant difference between CVVHD and CVVHDF in the reduction of leucine rates according to the CKRT duration [7].

Studies of the toxic metabolite reduction rates associated with CKRT have produced inconsistent results [5-7]. For instance, a study published in 2019 detected a mean duration of dialysis for hyperammonemia in UCD-diagnosed patients of 46 (33-53) h [5], while another study reported a mean duration of $19.4 \pm 16.4 \mathrm{~h}$ in a similar group of patients, and a mean ammonia reduction rate of $5.02 \pm 4.53 \%$ per hour for patients with organic acidemia [6]. The same study identified a mean leucine reduction rate of $3.88 \pm 3.65 \%$, while Demirkol et al. reported a mean leucine reduction rate of between $62.3 \%$ and $75.9 \%$, and a mean leucine reduction rate per hour of between $4.5 \%$ and $5.8 \%$ in different CKRT modalities [6, 7]. Moreover, the mean leucine reduction rate and the mean leucine reduction rate per hour were recorded as $83 \pm 6.6 \%$ and $4 \pm 2.5 \%$ for CVVHDF, respectively, in another study [7]. In the present study, a higher ammonia reduction rate and a lower mean ammonia reduction rate per hour than in previous studies were detected. In MSUD patients, lower leucine reduction rates and leucine reduction rates per hour were calculated, and we concluded that this diversity in findings could be attributed to the use of different CKRT modalities, the area of the membrane and the blood flow rate. Nevertheless, all studies reported CKRT to be a safe and effective approach to removing toxic metabolites in patients with IEM.

In a metabolic crisis, kidney function tests may be impaired, and metabolic acidosis, electrolyte imbalance, and dehydration may be observed. In the patients in the present study, abnormal levels of BUN, creatinine, sodium, potassium, and phosphate were detected, all of which improved with CKRT treatment. These findings support the suggestion that CKRT applied to patients with IEM not only removes toxic metabolites but also impairs electrolyte imbalance [21].

Despite all these advantages, providers need to be aware of the potential complications of CKRT, the most often reported of which are thrombocytopenia, hypotension, hypocalcemia, hypokalemia, hypothermia, complications of anticoagulation, complications due to vascular access such as bleeding, and thrombosis [20]. The disadvantages of CKRT relate primarily to technical difficulties, including complications in the insertion of catheters for neonates and infants, and low body-weight children. To avoid catheter complications, the most commonly preferred vascular line is the right internal jugular vein [20,21]. Consistently, in the present study, thrombocytopenia, hypotension, hypocalcemia, hypokalemia, and hypothermia were identified as the most common complications of CKRT, and similar to other studies, the right internal jugular vein $(67.8 \%)$ was commonly used for CKRT.

The development of hypotension following CKRT is common, with critically ill children being at greater risk than adults [22]. Generally, the CKRT circuits and lines usually used have an extracorporeal volume of over $10 \%$ of an infant's blood volume, meaning that there is a significant risk of hypotension, and priming with blood or albumin is required to prevent hypotension [23]. While one cohort has identified a global incidence of hypotension of $49.7 \%$, in a global survey, hypotension was observed in $18.8 \%$ of adult patients [23, 24]. In the light of this information, before the initiation of CKRT in the present study, blood, albumin, or physiological saline were used to prevent hypotension in all sessions. In the present study, hypotension occurred in more than half of patients, with the median age of those who developed hypotension being lower than that of the patients with normal blood pressure. As expected, vasoactive medications were more frequently used in young patients. These findings indicate that the risk of hypotension should be kept in mind in low weight and young patients. Furthermore, hypotension was more frequently observed in CVVHDF (75.0\%) than CVVHD (33.3\%), although this finding could 
be attributable to the lower age of patients under CVVHDF than those under CVVHD.

PIM, PIM2, and PIM3 scores, together with PRSIM III and PELOD 2, provided the most suitable indications of mortality, while PRISM provided the poorest mortality prediction of all the tested scores [25]. Based on the daily estimation of the severity of multiple organ dysfunction syndromes in critically ill children, a high PELOD score $(\geq 20$ points) was associated with a mortality rate of $40.7 \%$, and a low PELOD score ( $<10$ points) was associated with a mortality rate of $<1 \%$ on the first day of PICU admission [26]. Similar to this logistic regression model, in the present study the mean PELOD-2 score was higher in patients who died (22 [2-32]) despite the mean PELOD-2 score of all patients being $10[0-16.5]$. The study with the largest study population with IEM evaluated the relationship between PRISM III, PELOD-2 scores and mortality in CKRT, and reported the PELOD score to be lower in the surviving patients. However, in this study, the effectiveness of CKRT and the reduction rate of toxic metabolites were not evaluated [27]. To better understand the relationship between scores and mortality, larger study populations and meta-analyses are needed. Furthermore, the effect of other factors, such as the patients' age and weight, and the time interval between symptom emergence and CKRT initiation, on the outcome of CKRT should not be forgotten.

In the present study, we evaluated the relationship between the complications and outcomes of CKRT and the patients' age and identified no significant difference between mortality and age. As mentioned above, we believe this result to be associated with the increased experience of CKRT in young infants weighing $10 \mathrm{~kg}$ or less. One interesting finding of the present study is that the mortality rate in CVVHDF (50\%) is higher than for CVVHD (12.5\%), although we believe it is not necessary to take this into account as the diagnosis of more than half of the patients treated with CVVHDF was UCD, while more than half of the CVVHD treatments were performed on MSUD patients. One can imagine that a neonate with an undiagnosed UCD will be much sicker than an older child with a known MSUD. Studies including larger populations with the same diagnosis are essential to understand better the mortality rates associated with the two methods.

\section{Limitations of the study}

The present study has several limitations. First, it is a retrospective single-center study in which long-term outcomes were not followed up. Secondly, no evaluation was made of the parameters affecting the efficacy of CKRT, such as the area of the membrane and the blood flow rate. Finally, we believe the number of dialysis sessions should be higher to allow a comparison of subgroups and obtain more statistically significant results, despite this being one of the largest patient groups in literature in its area of interest.

\section{Conclusions}

In conclusion, CKRT can be considered a reliable approach to the effective and rapid removal of toxic metabolites in patients with IEM. Our study, in which the largest number of dialysis sessions reported to date is examined, showed that CKRT modalities can be used safely and are well-tolerated in infants as well as adults, although a considerable number of complications of CKRT were determined. Multicenter prospective studies are needed to confirm our findings.

Author contribution Fatma Tuba Eminoglu and Tanıl Kendirli contributed to the study conception, design and material preparation. Engin Kose and Ummuhan Oncul contributed to the study methodology and outcome assessments. Ummuhan Oncul and Engin Kose contributed to the study conception and wrote the first draft. Emel Okulu, Tanıl Kendirli, Fevzi Kahveci and Elvis Kraja contributed to the study methodology and conducted the dialysis therapy intervention. Ummuhan Oncul and Fevzi Kahveci contributed to the study design, data collection and analysis and manuscript preparation. All authors read and approved the final manuscript.

Data availability Data can be made available upon request.

Code availability Not applicable

\section{Declarations}

Ethics approval The study was approved by the Institutional Ethics Board of the Ankara University Faculty of Medicine (I5-304-20) and was conducted in accordance with the ethical and humane principles of research established by the Declaration of Helsinki.

Consent to participate Not applicable

Consent for publication Not applicable

Conflict of interest The authors declare no competing interests.

\section{References}

1. Häberle J, Burlina A, Chakrapani A, Dixon M, Karall D, Lindner M, Mandel H, Martinelli D, Pintos-Morell G, Santer R, Skouma A, Servais A, Tal G, Rubio V, Huemer M, Dionisi-Vici C (2019) Suggested guidelines for the diagnosis and management of urea cycle disorders: First revision. J Inherit Metab Dis 42:1192-1230. https://doi.org/10.1002/jimd.12100

2. Abily-Donval L, Dupic L, Joffre C, Brassier A, Arnoux JB, Grimaud M, Lesage F, de Saint BL, Bekri S, Marret S, Pontoizeau C, Renolleau S, Ottolenghi C, de Lonlay P, Oualha M (2020) Management of 35 critically ill hyperammonemic neonates: role of early administration of metabolite scavengers and continuous 
hemodialysis. Arch Pediatr 27:250-256. https://doi.org/10.1016/j. arcped.2020.05.002

3. Blackburn PR, Gass JM, Vairo FPE, Farnham KM, Atwal HK, Macklin S, Klee EW, Atwal PS (2017) Maple syrup urine disease: mechanisms and management. Appl Clin Genet 10:57-66. https:// doi.org/10.2147/TACG.S125962

4. Raina R, Bedoyan JK, Lichter-Konecki U, Jouvet P, Picca S, Mew NA, Machado MC, Chakraborty R, Vemuganti M, Grewal MK, Bunchman T, Sethi SK, Krishnappa V, McCulloch M, Alhasan K, Bagga A, Basu RK, Schaefer F, Filler G, Warady BA (2020) Consensus guidelines for management of hyperammonaemia in paediatric patients receiving continuous kidney replacement therapy. Nat Rev Nephrol 16:471-482. https://doi.org/10.1038/ s41581-020-0267-8

5. Celik M, Akdeniz O, Ozgun N, Ipek MS, Ozbek MN (2019) Short-term results of continuous venovenous haemodiafiltration versus peritoneal dialysis in 40 neonates with inborn errors of metabolism. Eur J Pediatr 829-836. https://doi.org/10.1007/ s00431-019-03361-4

6. Aygun F, Varol F, Aktuglu-Zeybek C, Kiykim E, Cam H (2019) Continuous renal replacement therapy with high flow rate can effectively, safely, and quickly reduce plasma ammonia and leucine levels in children. Child (Basel, Switzerland) 6:53. https:// doi.org/10.3390/children6040053

7. Demirkol D, Şık G, Topal N, Çıtak A, Zeybek Ç, Tüten A, Bilge I (2016) Continuous Venovenous Hemodiafiltration in the Treatment of Maple Syrup Urine Disease. Blood Purif 42:27-32. https://doi.org/10.1159/000443783

8. Hediger N, Landolt MA, Diez-Fernandez C, Huemer M, Häberle J (2018) The impact of ammonia levels and dialysis on outcome in 202 patients with neonatal onset urea cycle disorders. J Inherit Metab Dis 41:689-698. https://doi.org/10.1007/ s10545-018-0157-4

9. Leteurtre S, Duhamel A, Salleron J, Grandbastien B, Lacroix J, Leclerc F (2013) PELOD-2: an update of the PEdiatric logistic organ dysfunction score. Crit Care Med 41:1761-1773. https:// doi.org/10.1097/CCM.0b013e31828a2bbd

10. Pollack MM, Holubkov R, Funai T, Dean JM, Berger JT, Wessel DL, Meert K, Berg RA, Newth CJL, Harrison RE, Carcillo J, Dalton H, Shanley T, Jenkins TL, Tamburro R (2016) The Pediatric risk of mortality score: update 2015. Pediatr Crit care Med 17:2-9. https://doi.org/10.1097/PCC.0000000000000558

11. Richardson DK, Corcoran JD, Escobar GJ, Lee SK (2001) SNAPII and SNAPPE-II: Simplified newborn illness severity and mortality risk scores. J Pediatr 138:92-100. https://doi.org/10.1067/ mpd.2001.109608

12. Strazdins V, Watson AR, Harvey B (2004) Renal replacement therapy for acute renal failure in children: European guidelines. Pediatr Nephrol 19:199-207. https://doi.org/10.1007/ s00467-003-1342-7

13. Porta F, Peruzzi L, Bonaudo R, Pieretti S, Busso M, Cocchi E, Conio A, Pagliardini V, Spada M (2018) Differential response to renal replacement therapy in neonatal-onset inborn errors of metabolism. Nephrology (Carlton) 23:957-961. https://doi.org/ 10.1111/nep.13409

14. Cho H (2019) Renal replacement therapy in neonates with an inborn error of metabolism. Korean J Pediatr 62:43-47. https:// doi.org/10.3345/kjp.2018.07143

15. Ames EG, Luckritz KE, Ahmad A (2020) A retrospective review of outcomes in the treatment of hyperammonemia with renal replacement therapy due to inborn errors of metabolism. Pediatr Nephrol 35:1761-1769. https://doi.org/10.1007/ s00467-020-04533-3
16. Askenazi DJ, Goldstein SL, Koralkar R, Fortenberry J, Baum M, Hackbarth R, Blowey D, Bunchman TE, Brophy PD, Symons J, Chua A, Flores F, Somers MJG (2013) Continuous renal replacement therapy for children $\leq 10 \mathrm{~kg}$ : a report from the prospective pediatric continuous renal replacement therapy registry. J Pediatr 162:587-592.e3. https://doi.org/10.1016/j.jpeds.2012.08.044

17. Schiff M, Baulny HO de, Dionisi-Vici C (2016) Maple syrup urine disease, 1sovaleric aciduria, propionic aciduria, methylmalonic aciduria, 6th ed. Berlin

18. Alfadhel M, Al MF, Makhseed N, Al JF, Al-Thihli K, Al-Jishi E, AlSayed M, Al-Hassnan ZN, Al-Murshedi F, Häberle J, BenOmran T (2016) Guidelines for acute management of hyperammonemia in the Middle East region. Ther Clin Risk Manag 12:479-487. https://doi.org/10.2147/TCRM.S93144

19. Spinale JM, Laskin BL, Sondheimer N, Swartz SJ, Goldstein SL (2013) High-dose continuous renal replacement therapy for neonatal hyperammonemia. Pediatr Nephrol 28:983-986. https://doi. org/10.1007/s00467-013-2441-8

20. Sanderson KR, Harshman LA (2020) Renal replacement therapies for infants and children in the ICU. Curr Opin Pediatr 32:360-366. https://doi.org/10.1097/MOP.0000000000000894

21. Tandukar S, Palevsky PM (2019) Continuous renal replacement therapy: who, when, why, and how. Chest 155:626-638. https:// doi.org/10.1016/j.chest.2018.09.004

22. Menon S, Broderick J, Munshi R, Dill L, DePaoli B, FathallahShaykh S, Claes D, Goldstein SL, Askenazi DJ (2019) Kidney support in children using an ultrafiltration device: a multicenter, retrospective study. Clin J Am Soc Nephrol 14:1432-1440. https:// doi.org/10.2215/CJN.03240319

23. Fernández S, Santiago MJ, González R, Urbano J, López J, Solana MJ, Sánchez A, Del Castillo J, López-Herce J (2019) Hemodynamic impact of the connection to continuous renal replacement therapy in critically ill children. Pediatr Nephrol 34:163-168. https://doi.org/10.1007/s00467-018-4047-7

24. Uchino S, Bellomo R, Morimatsu H, Morgera S, Schetz M, Tan I, Bouman C, Macedo E, Gibney N, Tolwani A, Oudemans-van Straaten H, Ronco C, Kellum JA (2007) Continuous renal replacement therapy: a worldwide practice survey. The beginning and ending supportive therapy for the kidney (B.E.S.T. kidney) investigators. Intensive Care Med 33:1563-1570. https://doi.org/10. 1007/s00134-007-0754-4

25. Niederwanger C, Varga T, Hell T, Stuerzel D, Prem J, Gassner M, Rickmann F, Schoner C, Hainz D, Cortina G, Hetzer B, Treml B, Bachler M (2020) Comparison of pediatric scoring systems for mortality in septic patients and the impact of missing information on their predictive power: a retrospective analysis. PeerJ 8:e9993. https://doi.org/10.7717/peerj.9993

26. Leteurtre S, Duhamel A, Grandbastien B, Proulx F, Cotting J, Gottesman R, Joffe A, Wagner B, Hubert P, Martinot A, Lacroix J, Leclerc F (2010) Daily estimation of the severity of multiple organ dysfunction syndrome in critically ill children. CMAJ 82:1181-1187. https://doi.org/10.1503/cmaj.081715

27. Yetimakman AF, Kesici S, Tanyildiz M, Bayrakci B (2019) Continuous renal replacement therapy for treatment of severe attacks of inborn errors of metabolism. J Pediatr Intensive Care 08:164 169. https://doi.org/10.1055/s-0039-1683991

Publisher's note Springer Nature remains neutral with regard to jurisdictional claims in published maps and institutional affiliations. 